\title{
Estratégias de ensino aprendizagem em história da enfermagem na perspectiva dos estudantes: um estudo comparativo
}

\author{
Teaching strategies learning in nursing history from the perspective of \\ students: a comparative study
}

\author{
Ana Luiza Alves Moreira1; Maria Lelita Xavier²; Maritza Consuelo Ortiz Sanchez ${ }^{3}$ \\ 1 Enfermeira, Universidade do Estado do Rio de Janeiro, Rio de Janeiro, RJ, Brasil - annalu.alves@ hotmail.com/0000-0003- \\ 0406-889X \\ 2 Doutora em Enfermagem, Universidade do Estado do Rio de Janeiro, Rio de Janeiro, RJ, Brasil - \\ litaxprofessorauerj@gmail.com/0000-0003-3014-733X \\ 3 Doutora em Enfermagem, Universidade Federal Fluminense, Niterói, Rio de Janeiro, Brasil - \\ morsa_peru@yahoo.com/0000-0003-0131-9489
}

Recebido em Setembro/2019. Publicado em Abril/2020

\section{Palavras-chave:}

Ensino de Enfermagem.

História da enfermagem.

Estratégia de Ensino.

Enfermagem.

\section{Keywords:} Nursing teaching.. History of nursing. Teaching Strategy. Nursing.

\section{RESUMO:}

Objetivo: analisar comparativamente as estratégias, relacionando-as com os conteúdos implementados no primeiro e segundo semestres letivos de 2015, no ensino da História de Enfermagem, sob o ponto de vista dos estudantes. Método: estudo de caráter qualitativo, exploratório e com interface comparativa. Trata-se de um recorte do trabalho de conclusão de curso da autora. Os dados foram obtidos por meio de entrevista semiestruturada com os estudantes e dos planos de ensino das duas turmas da disciplina de História da Enfermagem do ano de 2015. Para a análise dos dados, utilizou-se a Análise de Conteúdo. Resultado: aponta para a percepção dos estudantes quanto às estratégias adotadas na ministração dos conteúdos do ensino de História da Enfermagem. Para a turma do primeiro semestre letivo, as estratégias de ensino foram adequadas, entretanto, ressaltaram que a presença de um especialista implicaria o melhor aproveitamento dos conteúdos ministrados. Em contrapartida, os estudantes da turma do segundo semestre letivo referiram que estas contribuíram para o aprendizado, favoreceram e estimularam a apreensão dos assuntos abordados. Conclusão: o sucesso do processo de ensino-aprendizagem é facilitado na introdução de estratégias que estejam em consonância com o ato pedagógico, e este visa a estimular, no estudante, a criatividade, autonomia e o pensamento crítico. Os estudantes entenderam que a utilização de tais estratégias contribuiu para a compreensão da História da Enfermagem e, sobretudo, para a sua formação.

ABSTRACT: Objective: To comparatively analyze the strategies relating them with the contents implemented in the first and second semesters School of 2015 in the teaching of nursing history from the point of view of students. Method: qualitative, exploratory character study and comparative interface. This is a clipping of the monography of the author. Data were collected through semi-structured interview with the students and the teaching plans of the two classes of the discipline of nursing history to the year 2015. For data analysis using the method of content analysis. Result: points to the students ' perception about the strategies adopted in the ministration of the contents of the teaching of the history of nursing. For the first school semester teaching strategies were appropriate, however stressed that the presence of an expert would in better use of the contents taught. On the other hand, students of his class in the second half have reported that these contributed to 
academic learning, favored and encouraged the seizure of the subjects discussed. Conclusion: the success of the teaching learning process occurs from the introduction of strategies that are in line with the pedagogical Act, this aims to stimulate student creativity, autonomy and critical thinking. Students understand that the use of these strategies contributed to the understanding of the history of nursing and, above all, for your training.

\section{INTRODUÇÃO}

O objeto deste estudo é a comparação do ensino da História da Enfermagem entre turmas de um curso de graduação sob o ponto de vista dos acadêmicos.

História da Enfermagem consiste no estudo do passado da profissão, entendendo os determinantes históricos que influenciam o exercício profissional e seus desdobramentos para a legitimação da profissão em seu presente e futuro, contribuindo para a compreensão e o aperfeiçoamento das práticas e conhecimentos que norteiam o cuidado (CAMPOS; MONTANARI, 2011).

O estudo da História da Enfermagem tem possibilitado, ao enfermeiro, contemplar sua profissão de forma a compreender suas capacidades e competências e a construir e a desmitificar a visão da identidade profissional vivida por eles. Dessa forma, a associação da Enfermagem e da história tem proporcionado a análise do passado da profissão e permitido interpretar e compreender a conjuntura atual, possibilitando a mudança dessa realidade por meio do ensino e das práticas assistenciais de Enfermagem (OGUISSO; CAMPOS, 2013).

O ensino de História da Enfermagem, no Brasil, perdura desde 1923 com a criação da Escola de Enfermagem Anna Nery, recebendo denominações diferentes ao longo do tempo, tais como: inicialmente, "Bases históricas, éticas e sociais da enfermeira"; em 1931, chamou-se Ética e História da Enfermagem; em 1949, História da Enfermagem. A sua inserção sobreviveu às diversas reformas curriculares de Enfermagem, do Parecer $\mathrm{n}^{\circ}$ 163/1972 e a Resolução n 04/1976, referentes ao currículo mínimo, assim como o Parecer no 314/1994 e a Portaria $n^{\circ}$ 1.721/1994, que dispunham sobre o mesmo tema (OGUISSO; CAMPOS, 2007). Esta última inclusa em Fundamentos de Enfermagem e assim mantida pela Resolução do Conselho Nacional de Educação (CNE)/Câmara de Educação Superior (CES) no 3, de 2001, a qual Instituiu as Diretrizes Curriculares Nacionais do Curso de Graduação em Enfermagem (DCENF) (BRASIL, 2001).

As Diretrizes Curriculares Nacionais servem de referência para as Instituições de Ensino Superior (IES) na organização de seus programas de formação, permitindo a flexibilização na construção dos currículos e privilegiando a indicação de áreas de conhecimento a serem consideradas. Ao invés de estabelecer disciplinas e cargas horárias definidas, tem sua origem na Lei de Diretrizes e Bases da Educação (LDB), de 1996 (XAVIER, 2010). 
A LDB regulamenta o campo da educação superior no país e confere às universidades "autonomia didático-científica, administrativa e de gestão financeira e patrimonial" (BRASIL, 1988), tendo, como norteadores do campo da educação superior, os aspectos centrais flexibilidade, competitividade e avaliação e, como princípios, a expansão, a diversificação, a avaliação e a modernização (BRASIL, 1996).

Desse modo, as DCENF orientam-se, principalmente, pelo aspecto da flexibilidade para a organização, para o funcionamento, para a estruturação dos cursos de Enfermagem e delimitam elementos conceituais, filosóficos e metodológicos que subsidiem a organização curricular do ensino de Enfermagem, apontando estratégias de ensino e aprendizado, motivando para propostas inovadoras à formação dos enfermeiros (XAVIER, 2010; FERNANDES, et. al., 2005).

$\mathrm{Na}$ instituição cenário desta pesquisa, desde a sua criação, em 1944, o ensino da História da Enfermagem sempre foi ministrado, mesmo quando não explicitada sua obrigatoriedade no Parecer $n^{\circ}$ 163/72, e manteve-se presente ao longo de sua trajetória. Com a reforma curricular institucional finalizada, em 1996, o ensino da história consolidou-se, passando a ser no quinto período do curso, com carga horária de 60 horas por período letivo, e a diretriz metodológica que norteia o processo de ensino-aprendizagem é a problematização que visa a superar a transmissão de conhecimentos, tornando o ato de educar um instrumento de intervenção e transformação da realidade. Assim, admite-se que cada indivíduo é único e pode contribuir, entretanto, fica a cargo do docente o planejamento para operacionalizar e inovar métodos de ensino que facilitem esse processo (UERJ, 2005; CORREIA, et.al. 2004).

A disciplina de História de Enfermagem utiliza-se de diversas estratégias que contemplam o modelo pedagógico da problematização e técnicas de ensino inovadoras, como oficinas, dramatização, dinâmica de grupos, vídeos e outros que possibilitam a participação e promovem a reflexão por parte dos alunos. Contudo, apesar da utilização destas abordagens, observou-se, muitas vezes, que os alunos ficavam pouco motivados e se limitavam a cumprir as atividades acadêmicas com pouco envolvimento. Entender essa dinâmica e vislumbrar que os resultados podem contribuir para o aprimoramento das aulas de História nos cursos de Enfermagem, no que diz respeito à utilização de estratégias de ensino e aprendizagem, fez-se primordial o que justifica o desenvolvimento deste estudo.

Nessa perspectiva, houve a necessidade de reformular o planejamento de ensino da História da Enfermagem ocorrido no segundo semestre letivo de 2015, o que implicou readequar conteúdos e estratégias de ensino, entendidas como o modo de organizar e transmitir determinados conhecimentos de forma a facilitar a apreensão de conteúdos e tornar o processo de aprendizagem analítico e estimulador de reflexões aplicáveis à realidade que 
fizessem sentido para a sua formação e contribuíssem para a construção da identidade profissional (BORDENAVE; PEREIRA 2014).

A partir dessas considerações, definiu-se como objetivo analisar comparativamente as estratégias, relacionando-as com os conteúdos implementados no primeiro e segundo semestres letivos de 2015, no ensino da História de Enfermagem, sob o ponto de vista dos estudantes.

\section{METODOLOGIA}

Trata-se de um estudo descritivo com abordagem qualitativa e com interface comparativa. O cenário foi uma instituição estadual de ensino superior do Rio de Janeiro. Para a coleta de dados, utilizaram-se a entrevista semiestruturada e os planos de ensino dos períodos letivos estudados.

Participaram deste estudo 20 estudantes, sendo 12 de uma turma e oito de outra. Ressalta-se que este artigo é originário do Trabalho de Conclusão de Curso (TCC) de Graduação em Enfermagem da autora e as entrevistas utilizadas foram aquelas representativas do recorte em estudo.

Os critérios de inclusão: estarem regularmente matriculados e terem vivenciado o ensino de História de Enfermagem no ano de 2015. Como critérios de exclusão: estudantes vinculados a projetos de extensão e/ou monitoria na área de História da Enfermagem.

Assinou-se, antecedendo a realização da entrevista, pelos participantes, o Termo de Consentimento Livre e Esclarecido (TCLE), que expõe o objeto, objetivos, benefícios, riscos e garantia do anonimato. As entrevistas foram gravadas em meio digital e transcritas para sua posterior análise.

Para preservar o anonimato dos participantes, estes foram identificados com a letra $\mathrm{E}$ seguida do numeral correspondente à ordem das entrevistas realizadas e das siglas SL1, referente ao primeiro semestre letivo, e SL2, ao segundo semestre letivo de 2015.

Esta pesquisa foi realizada em conformidade com os preceitos éticos legais, sendo aprovada pelo Comitê de Ética e Pesquisa da Universidade Estadual do Rio de Janeiro (UERJ) por meio do parecer de número 1.660.722/2016.

Utilizou-se a técnica de Análise de Conteúdo, caracterizada como um conjunto de métodos de análise de comunicações que examinam o conteúdo das descrições a fim de atribuir-lhes sentidos e significados (BARDIN, 2011).

\section{RESULTADOS E DISCUSSÃO}


A inovação educacional é o início de uma nova forma de se fazer educação e produzir conhecimento, tem como proposta tornar o estudante universitário sujeito do processo de aprendizagem, alterando radicalmente a disposição anterior de se entregar todas as informações já prontas e sistematizadas pelo professor para a memorização e reprodução (MASETTO, 2004).

Corrobora-se essa assertiva, de acordo com as Diretrizes Nacionais Curriculares propostas em 2001 pelo Conselho Nacional de Educação, pelo currículo do Curso de Graduação em Enfermagem da UERJ, que primou pela incorporação das metodologias ativas no Projeto Pedagógico do Curso (PPC), que favorece a formação de enfermeiros cidadãos, atuantes na resolução de problemas encontrados em sua realidade, comprometidos com a vida, pautados nos princípios éticos e legais que norteiam a profissão (BRASIL, 2001 ; UERJ, 2005).

Nesse sentido, as áreas de conhecimento que compõem o PPC estão em constante adequação no que tange à inovação e mudança, alinhando-as com a realidade e a necessidade do contexto educacional, o que fica evidenciado na reorganização do plano de ensino da História de Enfermagem. Este vinha, ao longo do tempo, priorizando algumas temáticas que ocupavam maior carga horária em detrimento de outras que tivessem maior significado para os estudantes, exemplificando: aquelas relacionadas às práticas de saúde da profissão no decorrer de sua trajetória histórica; além de mudança nas práticas educacionais, adequando-as à metodologia que já era utilizada no ensino de História de Enfermagem.

Tais mudanças relativas às temáticas abordadas em relação às metodologias utilizadas seguem organizadas no quadro 1.

\section{Quadro 1. Demonstrativo das estratégias e temáticas dos planos de ensino das turmas do primeiro e segundo semestres letivos 2015. Rio de Janeiro, 2017.}

\begin{tabular}{|l|l|l|}
\hline \multicolumn{1}{|c|}{$\begin{array}{c}\text { Estratégias } \\
\text { utilizadas }\end{array}$} & Turma do primeiro semestre letivo de 2015 & \multicolumn{1}{c|}{ Turma do segundo semestre letivo de 2015 } \\
\hline Oficina & Primórdios dos cuidados. & $\begin{array}{l}\text { Personalidades da Enfermagem: Florence Nigthingale; } \\
\text { Anna Nery; Rachel Haddock Lobo e Wanda Horta. }\end{array}$ \\
\hline Visita guiada & $\begin{array}{l}\text { Enfermagem profissional no Brasil: século 21 e } \\
\text { atual; Centro de Memória Nalva Pereira Caldas. }\end{array}$ & $\begin{array}{l}\text { A importância dos } \\
\text { históricos da Enfermagem. }\end{array}$ \\
\hline Seminário & $\begin{array}{l}\text { Criação de Escolas de Enfermagem } \\
\text { Brasileiras; Criação da Escola de Enfermagem } \\
\text { Rachel Haddock Lobo - FENF/UERJ; Criação } \\
\text { do currículo da UERJ; Biografia Nalva Pereira } \\
\text { Caldas; Criação do mestrado e doutorado da } \\
\text { UERJ; Criação da Residência em Enfermagem. }\end{array}$ & $\begin{array}{l}\text { Criação de Escolas de Enfermagem Brasileiras; } \\
\text { Criaça da Escola de Enel Haddock Lobo da UERJ; Criação do currículo } \\
\text { Rachel } \\
\text { da Enfermagem da UERJ; Biografia de Nalva Pereira } \\
\text { Caldas; Criação do Centro de Memória da Enfermagem } \\
\text { da UERJ; Criação do internato da UERJ. }\end{array}$ \\
\hline $\begin{array}{l}\text { Aula } \\
\text { expositiva/diálogo } \\
\text { circular }\end{array}$ & $\begin{array}{l}\text { Criação da Aben e Coren; Enfermeira brasileira } \\
\text { na II Guerra Mundial e nas Forças Armadas. }\end{array}$ & $\begin{array}{l}\text { História da Psiquiatria; Enfermagem e os órgãos de } \\
\text { classe; A Enfermagem nas Forças Armadas e } \\
\text { Enfermeiras na II Guerra Mundial. }\end{array}$ \\
\hline Monitoria & $\begin{array}{l}\text { Utilizada durante todo o processo de ensino- } \\
\text { aprendizagem. }\end{array}$ & $\begin{array}{l}\text { Utilizada durante todo o processo de ensino- } \\
\text { aprendizagem. }\end{array}$ \\
\hline
\end{tabular}

Elaborado pelos autores, 2018. 
Realizou-se, tendo em vista que, na condução do processo pedagógico, os estudantes possuem experiências singulares, que cada indivíduo é único em sua forma de pensar e se posicionar perante as diversas situações e considerando que, entre os planos de ensino das turmas, há pontos de similitudes e diferenças, a análise da percepção dos estudantes de ambas as turmas quanto às estratégias de ensino que foram adotadas no decorrer do ano letivo de 2015, tomando-as por base como critérios de comparação.

A oficina pedagógica constitui-se em uma metodologia de ensino que possui foco maior na ação sem, contudo, desconsiderar a teoria e oportuniza, ao estudante, vivenciar situações de forma palpável a partir de uma teoria pré-estabelecida com base na tríade sentirpensar-agir (PAVIANI; FONTANA, 2009).

$\mathrm{Na}$ disciplina, esta estratégia de ensino foi utilizada no primeiro semestre letivo de 2015 para abordar os conteúdos de primórdios do cuidado e, no segundo semestre letivo do mesmo ano, para abordar sobre as personalidades da Enfermagem.

Para alguns estudantes da turma do primeiro semestre letivo de 2015, não pareceu ser a melhor estratégia porque o conhecimento acerca de sua própria oficina é que ficou melhor evidenciado em detrimento do que os demais grupos apresentaram.

[...] porque as oficinas, por mais que aprendemos e fazemos trabalhos e essas coisas, mas você busca mais o seu. (E3SL1)

Infere-se que a cultura da transmissibilidade do conhecimento a partir da hierarquização do saber, onde o docente é o detentor do conhecimento e o estudante é o receptáculo, ainda está impregnada na sociedade (FREIRE, 2019).

A turma do segundo semestre letivo, ao contrário da turma anterior, considerou as oficinas enquanto estratégias adequadas, pois, de acordo com os discursos, foi possível o estímulo da criatividade e do senso crítico.

Na oficina, quando fazemos a dinâmica, incentiva o colega a pensar, responder às questões, como era a teoria tal. Eu acho que deu maior possibilidade de sermos mais criativo. (E5SL2)

Ao mesmo tempo que expõe aquele conteúdo pesquisado, os outros dão aquele retorno. Acho que fixa melhor quando fazemos assim. (E14SL2)

Têm-se, então, a articulação da apropriação, a construção e a produção de conhecimentos de forma ativa e reflexiva, incentivando a participação, organização e planejamento das atividades, pois se altera o foco da aprendizagem da cognição para a reflexão e a ação (PAVIANI; FONTANA, 2009).

Para as duas turmas, foi utilizada a visita guiada como estratégia de ensino no que diz respeito ao conhecimento sobre a "importância dos monumentos históricos de Enfermagem", “importância dos documentos históricos" e "Enfermagem profissional no Brasil”, que foi efetivada por meio da visita ao Pavilhão de Aulas da Escola de Enfermagem 
Anna Nery, que promoveu a aproximação das aulas teóricas com a realidade, visando a explorar o potencial educativo dos elementos históricos expositivos (documentos e monumentos) na instituição visitada. Seguem algumas falas extraídas da entrevista dos participantes.

A visita técnica à escola da UFRJ também é bem interessante porque você pega um pouco a história e sai de dentro da sala, você desenvolve interesse maior no estudante. (E7SL1)

Eu acho que foi uma coisa a mais (a visita guiada) que me fez gostar da História de Enfermagem e foi muito relevante mesmo. É até uma estratégia que a professora utilizou para nos incentivar a buscar outras coisas, buscar novos conhecimentos. (E5SL2)

A visita guiada constitui uma metodologia de ensino que permite, ao estudante, a aproximação do arcabouço teórico com o espaço histórico de forma lúdica, promovendo associações entre a teoria e sobre o que ela trata (ARAÚJO; QUARESMA, 2014).

Os temas que tratam da "Criação das escolas de Enfermagem brasileiras; Criação da ENF/UERJ, do currículo da UERJ e da biografia da professora Nalva Pereira Caldas" foram desenvolvidos utilizando as seguintes estratégias: seminário para a turma do primeiro semestre e mesa redonda para a turma do segundo semestre letivo. A seguir, os comentários acerca destas estratégias utilizadas.

Acho que seminário é importante porque realmente temos que correr atrás do conteúdo, nós precisamos saber melhor também, mas eu acho também que precisamos ter um guia. (E10SL1)

Os seminários foram bem legais porque os alunos se interessam pelo conteúdo. (E07SL1)

O seminário, enquanto estratégia de ensino, é muito conhecido pelos estudantes, no entanto, sua importância no processo pedagógico ainda é pouco evidenciada e algumas vezes reduzida (GIL, 2018). Trata-se de uma técnica que fomenta a pesquisa, comunicação e a reflexão coletiva a partir da temática a ser abordada, além de fundamentar a postura crítica dos estudantes, preparando-os para fundamentar seus posicionamentos no futuro profissional e defendendo a autonomia de suas práticas frente aos usuários e outros profissionais.

Na disciplina, a professora pregava bastante a pesquisa; deu para perceber que é realmente importante, mas ainda assim as publicações estão com uma certa deficiência com relação a tema. (E13SL2)

Ao adotar, como estratégia, a aula expositiva para alguns temas, tais como "Enfermagem e os órgãos de classe", "A enfermeira brasileira na II Guerra Mundial" e "Enfermagem nas Forças Armadas", seguida pelo diálogo circular, o educador deve considerar a explanação do conteúdo uniformemente à turma, possibilitando, ao aluno, agregar mais conhecimento a partir da discussão dos diversos pontos de vista acerca do tema abordado. A esse respeito, os participantes relatam o seguinte.

Elas (professoras) davam muita liberdade para trazermos o que conhecíamos e então ia montando (a discussão) em cima daquilo que trazíamos. (E22SL1) 
O fato de conversar, debater em sala de aula é importante também porque a gente pôde trazer o que cada um sabe, o conhecimento prévio de cada um. Você ia discutindo e vendo o pensamento das outras pessoas e, no decorrer, a professora ia conduzindo como era, então, partimos do princípio que tínhamos conhecimento prévio. Ela dava a matéria e, no final, a entendíamos melhor. (E13SL2)

As práticas pedagógicas na educação traduzem-se em meios de controle social pela formação individual e coletiva, são caracterizadas pela aglutinação das particularidades do indivíduo enquanto facilitador da aprendizagem (docente) e da cultura institucional (FRANCO, 2015). Deve o educador, tendo em vista o projeto pedagógico instituído na Faculdade de Enfermagem da UERJ, apoiar-se em estratégias que proporcionem, aos estudantes, autonomia, criatividade, pensamento crítico e capaz de refletir sobre a realidade (UERJ, 2005).

A monitoria foi citada como uma estratégia facilitadora do aprendizado à medida que as monitoras davam suporte aos alunos nas reposições de conteúdos e nas orientações para a realização das atividades. Em um primeiro momento, os estudantes não compreendiam a necessidade da presença de um monitor na subárea, conforme emergiram nas falas abaixo.

A monitoria possibilita que os alunos se interessem pelo conteúdo, eles (monitores) formulam, junto com o professor, a aula. (EO7SL1)

Eu consegui compreender qual era o verdadeiro motivo das monitoras ali, elas estavam ensinando e nós estávamos aprendendo junto com elas e vice e versa. (E13SL2)

Ressalta-se que, na pedagogia da problematização, ninguém possui o monopólio do conhecimento, ao contrário, todos o possuem e são convidados a construí-lo (FREIRE, 2019). Dessa forma, faz-se necessário que o docente possa se utilizar de estratégias que ofereçam, aos estudantes, as bases que possam fundamentar e consolidar o conhecimento a partir da pesquisa, tendo o docente a tarefa de supervisionar e oferecer as bases teóricas necessárias para satisfazer os objetivos inicialmente traçados.

Ambas as turmas relatam que as estratégias de ensino adotadas contribuíram para o aprendizado, favoreceram e estimularam a apreensão de conteúdo. A turma do segundo semestre letivo de 2015, porém, acrescenta que estas agem como potencializadoras de habilidades e talentos do estudante. Aliado a isso, os alunos destacam o interesse pela pesquisa a partir das estratégias desenvolvidas.

Na comparação sobre as estratégias de ensino na percepção dos acadêmicos, algumas diferenças e semelhanças foram evidenciadas conforme aponta o quadro 2.

Quadro 2. Síntese comparada das estratégias de ensino na percepção dos acadêmicos das turmas do primeiro e segundo semestres de 2015. Rio de Janeiro, 2017. 
Ensino, Saúde e Ambiente - V13 (1), pp. 84-95, ABR. 2020

\begin{tabular}{|c|c|c|}
\hline $\begin{array}{l}\text { Critérios de } \\
\text { Comparação }\end{array}$ & Características 2015.1 & Características 2015.2 \\
\hline Oficina & $\begin{array}{l}\text { Forma lúdica de se compreender a temática. } \\
\text { Aprendizagem pontual referente ao próprio } \\
\text { tema. }\end{array}$ & $\begin{array}{l}\text { Estimulou a produção de conhecimento, a pesquisa } \\
\text { e a contextualização histórica dos temas abordados. }\end{array}$ \\
\hline Visita Guiada & $\begin{array}{l}\text { Aproximação dos estudantes à realidade } \\
\text { histórica. }\end{array}$ & $\begin{array}{l}\text { Fomenta o interesse dos estudantes pela História da } \\
\text { Enfermagem. }\end{array}$ \\
\hline Seminário & $\begin{array}{l}\text { Desenvolvimento da temática por meio de suas } \\
\text { próprias pesquisas. }\end{array}$ & $\begin{array}{l}\text { Estimula o debate e a reflexão dos temas abordados } \\
\text { quando conduzidos por especialistas. }\end{array}$ \\
\hline $\begin{array}{l}\text { Aula expositiva/ } \\
\text { Diálogo circular }\end{array}$ & 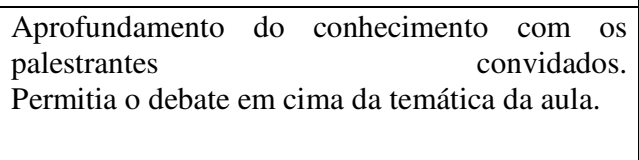 & $\begin{array}{l}\text { Válida a experiência desde que o palestrante } \\
\text { incentive a participação dos estudantes. } \\
\text { Agrega conhecimentos a partir da perspectiva dos } \\
\text { colegas de turma acerca das temáticas abordadas. }\end{array}$ \\
\hline Monitoria & $\begin{array}{l}\text { Aproximação/complementação dos assuntos } \\
\text { trabalhados em sala de aula. }\end{array}$ & $\begin{array}{llrr}\text { Aproximação/complementação } & \text { dos } & \text { assuntos } \\
\text { trabalhados em sala } & \text { de } & \text { aula. } \\
\text { Facilita o processo de ensino-aprendizagem. }\end{array}$ \\
\hline
\end{tabular}

Elaborado pelos autores, 2018.

\section{CONCLUSÃO}

A História da Enfermagem na UERJ é um saber inerente e imprescindível à formação de enfermeiros e fundamenta a sua prática. É a partir dos conhecimentos sobre a história que o profissional compreende sua profissão e tem a oportunidade de romper os paradigmas estabelecidos pelas relações de poder existentes nos diversos nichos da sociedade.

Entende-se, ainda, que o ensino de História da Enfermagem se constitui em uma forma de promover o fortalecimento da identidade do enfermeiro. Desse modo, o seu ensino deve ser valorizado e incentivado no âmbito dos cursos de graduação em Enfermagem.

Os estudantes participantes deste estudo reconhecem a importância das estratégias de ensino utilizadas como primordiais para a compreensão da História da Enfermagem. Estas são fatores essenciais ao processo pedagógico, uma vez que possibilitaram o desenvolvimento da afinidade dos estudantes com a área e de sua consciência crítica por meio do debate, da pesquisa, da organização e planejamento das atividades.

Ambas as turmas acreditam que as estratégias são problematizadoras e permitem, ao aluno, participar ativamente do processo de ensino-aprendizagem, que não é algo estático e entediante, mas estimula o debate e a autonomia, além de facilitar a apreensão dos conteúdos e tornar o estudante protagonista do seu aprendizado. A diversidade de estratégias de ensino, além de contribuir para despertar habilidades e potencialidades dos estudantes, os incentiva e cativa ao estudo da História da profissão.

Finalmente, este trabalho pode motivar os docentes da área da história a aplicar estratégias de ensino que fortaleçam, no estudante, a criatividade e a produção do pensamento pautado na reflexão para a ação. 
Ensino, Saúde e Ambiente - V13 (1), pp. 84-95, ABR. 2020

\section{REFERÊNCIAS:}

BARDIN, L. Análise de Conteúdo. Almedina: Edições 70, LDA, 2011. 280p.

BRASIL. Ministério da Educação. Resolução CNE/CES nº 3 de 07 de novembro de 2001. Institui Diretrizes Curriculares Nacionais do Curso de Graduação em Enfermagem. Diário Oficial da União. Brasília, DF, 09 nov. 2001. Seção 1, p. 37. Disponível em: $<$ http://portal.mec.gov.br/cne/arquivos/pdf/CES03.pdf>. Acesso em 23 fev. 2018.

ARAÚJO, G. D.; QUARESMA, A. G. Visitas guiadas e visitas técnicas: tecnologia de aprendizagem no contexto educacional. Competência. Porto Alegre, RS, v.7, n.2, p. 29-51, jul./dez. 2014. Disponível em

<http://seer.senacrs.com.br/index.php/RC/article/viewFile/175/196> Acesso em 07 jan 2017.

BORDENAVE, J. D. PEREIRA, A. M. Estratégias de Ensino Aprendizagem. 33 ed. Petrópolis: Editora Vozes, 2014. 360p.

CAMPOS, P. F. S.; MONTANARI, P. M. História social da enfermagem. In: OGUISSO, T. CAMPOS, P. F. S. FREITAS, G. F. Pesquisa em História da Enfermagem. 2 ed. Barueri: Editora Manole, 2011.

CORREIA, L. M. et al. Construção do projeto pedagógico: experiência da faculdade de Enfermagem da UERJ. Rev. Bras. Enferm., Brasília, v.57, n.6, p.649-53, nov./dez. 2004. Disponível em: http://www.scielo.br/pdf/reben/v57n6/a02.pdf. Acesso em 27 abr. 2016.

FRANCO, M. A. S. Práticas pedagógicas de ensinar-aprender: por entre resistências e resignações. Educ. Pesqui., São Paulo, v. 41, n. 3, p. 601-614, jul./set. 2015. Disponível em http://www.scielo.br/pdf/ep/v41n3/1517-9702-ep-41-3-0601.pdf. Acesso em 07 jan. 2018.

FERNANDES, J.D. et.al. Diretrizes curriculares e estratégias para implantação de uma nova proposta pedagógica. Rev Esc Enferm USP. São Paulo, 39(4):443-9. 2005. Disponível em http://www.scielo.br/pdf/reeusp/v39n4/10.pdf. Acesso em 07 fev. 2020.

FREIRE, P. Pedagogia do Oprimido. 50 ed. São Paulo: Editora Paz e Terra, 2019.256p.

GIL, A. C. Didática do ensino superior. $2^{a}$ ed. São Paulo: Atlas, 2018. 264p.

MASETTO, Marcos. Inovação na Educação Superior. Interface (Botucatu), Botucatu, v. 8, n. 14, p. 197-202, Feb. 2004 . Disponível em:

http://www.scielo.br/scielo.php?script=sci_arttext\&pid=S1414-

32832004000100018\&lng=en\&nrm=iso. Acesso em 21 fev. 2018.

OGUISSO, T.; CAMPOS, P. F. S. Por que e para que estudar história da enfermagem.

Enfermagem em Foco, Brasília, v.4, n.1, p. 49-53, Fev. 2013. Disponível em:

http://revista.portalcofen.gov.br/index.php/enfermagem/article/view/503. Acesso em 07 jan 2018

OGUISSO, T.; CAMPOS, P. F. S. História da enfermagem: reflexões sobre o ensino e a pesquisa na graduação. Rev Latino-am Enfermagem; 15(1). Janeiro/fevereiro. 2007. Disponível em http://www.scielo.br/scielo.php?pid=S0104-

11692007000100026\&script=sci_arttext\&tlng=pt. Acesso em 21 fev. 2020.

PAVIANI, N. S. FONTANA, N. M. Oficinas pedagógicas: relato de uma experiência.

Conjectura. Caxias do Sul, v. 14, n. 2, p. 77-88, maio/ago. 2009. Disponível em 
http://abenfisio.com.br/wp-content/uploads/2016/05/Oficinas-Pedagógicas.pdf Acesso em 07 jan 2018

UNIVERSIDADE DO ESTADO DO RIO DE JANEIRO (UERJ). Faculdade de Enfermagem. Projeto político pedagógico. Rio de Janeiro: UERJ, 2005.

XAVIER, M.L. A Reconfiguração do Campo da Educação Superior de Enfermagem no Estado do Rio de Janeiro: 1996-2006. Tese (Doutorado em Enfermagem) - Escola de Enfermagem Anna Nery, Universidade Federal do Rio de Janeiro. Rio de Janeiro: UFRJ / EEAN, Rio de Janeiro, p. 257. 2010. 


\section{SOBRE OS AUTORES}

Este item só deve ser incluído na versão final, após a avaliação por pares.

Apresentar um resumo da biografia de cada autor e especificar a participação de cada um na elaboração do estudo apresentado. (Times New Roman, Tamanho 12, espaçamento entre linhas simples, parágrafo justificado).

\section{ANA LUIZA ALVES MOREIRA}

Formada pela Faculdade de Enfermagem da Universidade do Estado do Rio de Janeiro. Especializanda em Enfermagem em Emergência e Terapia Intensiva, Professora na Escola Técnica Vencer, Enfermeira no Hospital Universitário Clementino Fraga Filho; integrante do Grupo de Estudos em História da Enfermagem e da Saúde da Universidade Estadual do Rio de Janeiro (UERJ). possui produções na área de Ensino, História da Enfermagem e Enfermagem em Terapia Intensiva e Emergência. Neste artigo contribuiu com a escrita do material, coleta e análise dos dados.

\section{MARIA LELITA XAVIER}

Doutora em enfermagem pela universidade federal do rio de janeiro (2010). Mestre em enfermagem pela escola de enfermagem alfredo pinto da universidade federal do estado do rio de janeiro - Unirio (1999). Graduada em enfermagem pela Unirio (1983). Membro do núcleo de pesquisa de história da enfermagem brasileira - (Nuphebras) da UFRJ. Membro do departamento científico de história da enfermagem da associação brasileira de enfermagem seção RJ (2016) e suplente do mesmo (2017). Coordenadora do grupo de estudos independente em história de enfermagem da UERJ. Tem experiência na área de enfermagem, com ênfase em administração e saúde mental em enfermagem. Atua como professora adjunta do Departamento De Fundamentos De Enfermagem Da Faculdade De Enfermagem - UERJ, nas disciplinas de administração e história de enfermagem.

\section{MARITZA CONSUELO ORTIZ SANCHEZ}

Enfermeira. Dra. em Enfermagem. Professora Adjunto do Departamento de Fundamentos de Enfermagem e Administração da Escola de Enfermagem Aurora de Afonso Costa da Universidade Federal Fluminense - Niterói-RJ (MFE/EEAAC/UFF). Pesquisadora do Núcleo de Pesquisa Cidadania e Gerência da EEAAC/UFF. Membro do Grupo de Estudos em História da Enfermagem e da Saúde da Universidade Estadual do Rio de Janeiro (UERJ). Neste artigo contribuiu com a avaliação e revisão do material. 